Article

\title{
Determining Soil Nutrients Reference Condition in Alpine Region Grassland, China: A Case Study of Hulun Buir Grassland
}

\author{
Jiaxun Li ${ }^{1,2, *}$, Feifei Cao ${ }^{1,2}$, Di Wu ${ }^{3}$, Xiao Fu ${ }^{1}$, Ye Tian ${ }^{4}$ and Gang Wu ${ }^{1,2, * \mathbb{C}}$ \\ 1 State Key Laboratory of Urban and Regional Ecology, Research Center for Eco-Environmental Sciences, \\ Chinese Academy of Sciences, Beijing 100085, China; ffcao_st@rcees.ac.cn (F.C.); xiaofu@rcees.ac.cn (X.F.) \\ 2 University of Chinese Academy of Sciences, Beijing 100049, China \\ 3 Institute of Architecture Design and Research, Chinese Academy of Sciences, Beijing 100086, China; \\ dwu@iue.ac.cn \\ 4 State Key Laboratory of Remote Sensing Science, Institute of Remote Sensing and Digital Earth, \\ Chinese Academy of Sciences, Beijing 100083, China; tianye@radi.ac.cn \\ * Correspondence: jxli_st@rcees.ac.cn (J.L.); wug@rcees.ac.cn (G.W.); Tel.: +86-010-6284-9190 (G.W.)
}

Received: 20 November 2018; Accepted: 5 December 2018; Published: 7 December 2018

\begin{abstract}
Grasslands represent a source of nutrient cycling, ecosystem stabilization, and services for human use. Grassland soil quality is commonly used as an indicator of ecosystem health and sustainability due to its strong correlation with overall grassland quality and ecosystem health. Although direct and indirect effects of human activities or disturbances on soil can be taken into account, a benchmark (i.e., the reference condition (RC)) should be used and is needed to describe the baseline of an area without significant anthropogenic disturbance. Therefore, determination of the soil reference condition and suitable selection methods have become a key focal point in grassland protection and ecological assessments. In this study, several methods were selected to determine soil nutrient concentrations of Hulun Buir Grassland in northern China based on the proposed criteria. The concentrations of total organic matter, N, P, and K; 112 samples were analyzed using the population distribution method, trisection method, and regression model method. The reference concentrations of total organic matter, N, P, and K in soil were recommended to be $52.12 \mathrm{~g} / \mathrm{kg}, 2.94 \mathrm{~g} / \mathrm{kg}, 2.08 \mathrm{mg} / \mathrm{kg}$, and $305.76 \mathrm{mg} / \mathrm{kg}$, respectively. In the alpine region grassland, the major factors that impact nutrient concentration were agricultural activity and vegetation coverage. Sampling methods should be used preferentially in determining grassland soil reference condition and historical data; experts' judgment could be used in substitution.
\end{abstract}

Keywords: ecological assessment; reference condition; grassland; soil quality

\section{Introduction}

Grassland covers a total area of 41-56 million $\mathrm{km}^{2}$, accounting for $\sim 40 \%$ of the earth's land surface (excluding Greenland and Antarctica) [1]. As a vital terrestrial ecosystem, grassland plays an important role in the carbon sequestration, modulating global climate, and performing ecosystem functions [2,3]. As one of the highly taxonomic units in the vegetation classification system, grass is formed under semi-arid and semihumid climate conditions and has many ecological functions that sustain the ecological balance and processes, such as providing nutrients, water and soil conservation, sand fixation, carbon fixation, and oxygen release [4]. However, increased anthropogenic disturbance and intervention has exacerbated overgrazing, soil erosion, desertification, and destruction of aquifer resources [5-7]. How to evaluate the degree of damage has thus become a key tenet of grassland protection management and environment sustainable development. Soil serves as a growth medium or 
habitat for most plants and microbes and acts as an effective environmental filter [8]. The nutrients in soil are the nourishment bank of terrestrial plants and are decisive factors in maintaining good physical properties of soil [9]. Good quality soil as part of a "sustainable grassland ecosystem" is defined by its ability to maintain an appropriate concentration of nutrients [10]. Due to the high sensitiveness of grassland ecosystems to anthropogenic disturbance, indicators such as nutrients in soil need to be considered in soil health quality ecological assessment [11].

The reference condition is often employed to describe the status of grasslands in the absence of human disturbance or alteration [12-14], idealistically representing the least impacted conditions. The reference condition provides both identification and indication of anthropogenic stressors and offers quantitative data of recovery plans and implementing legislative mandates [15]. Since the 1980s, many scientists have done research on the concepts, methods, and contents of the reference condition. Most studies focused primarily on the ecosystems of rivers, lakes, and streams [16-20], and the study contents included total phosphorus (TP), total nitrogen (TN), chlorophyll- $\alpha$, and other nutrients [21,22]. Forests, grassland, wetland, and species assemblages reference conditions were also studied [23-26], with the indicators of ecological structure, index, landscape patterns, etc. [27-29]. However, the relationship between nutrient reference concentrations and general concentration varied largely between ecoregion to ecoregion [30], and no universal method was adopted for study comparison.

Several methods have been suggested for establishing the reference condition. While qualitative analysis with expert judgment and historical data methods have primarily been used, many grassland areas that lack detailed historical data or can only provide an incomplete characterization of soils or species can be very prohibitive [31]. Expert judgment method was highly subjective, causing a huge deviation between observations and more quantitative methods [32]. The third method was to use descriptive statistics, such as 25 th percentiles of frequency distribution method and the trisection method [33]. The specific percentile of nutrients will assure the majority of the sample data will not exceed the reference thresholds. The United States Environmental Protection Agency (U.S.EPA) and European Union's Water Framework Directive (WFD) recommended these methods and have published several manuals or guidance to assess the reference condition [34,35]. The problem of descriptive statistics method was its sensitivity to the proportion of impacted sites and limited applicability for medium and large areas $[18,36]$. The fourth method was to estimate the reference condition by means of a multiple linear regression $[37,38]$. This method had been widely used with minimal anthropogenic impacts and without substantial modeling expertise. However, this method requires determining the factors that affect the variables and selected targeted factors to improve the model regression accuracy [34].

In China, grasslands are distributed in alpine regions on a large scale [39], and are regarded as ecologically vulnerable areas. In recent years, these vulnerable areas have become even more fragile due to increases in population density, rapid development of agriculture lands, and unreasonable exploitation of coal [40]. In recent decades, the Baorixile open-pit coal mine constructed in the center of Hulun Buir Grassland area has caused severe destruction of local biological habitat and soil erosion. This is in addition to, intense agricultural and grazing activities effects on the local ecosystem soil erosion [41]. According to the local government report in 2016, combined degradation, desertification, and salinization had reached 46 million hectares, accounting for $62.68 \%$ of the total Hulun Buir Grassland area. Once destroyed, grassland soil remediation efforts are extremely difficult, so a suitable soil quality monitoring and control program was urgently needed to prevent further grassland deterioration. Since detailed nutrient data and technical guidelines have also not been published regarding this local area, determination of the soil reference condition of the Hulun Buir Grassland is an important tool for environmental management and to set current and future goals and regulation for grasslands. A scientific-based determining method can also provide a fundamental objective to ecological assessments and evaluate whether impact factors are considered singly or in combination. This study took the grassland soil nutrients as the object of the research, and took Hulun 
Buir Grassland in northern China as the study area, using the population distribution method (PDM), trisection method (TM), and regression model method (RMM) to determine the reference condition. The objectives of this study are to (1) select the suitable determining methods for grassland ecosystem, (2) provide soil nutrients reference condition in study area, and (3) develop appropriate methods determination order of grassland soil nutrients reference condition.

\section{Materials and Methods}

\subsection{Study Area}

The study area is in the city of Hulun Buir $\left(115^{\circ} 31^{\prime} \mathrm{E}-126^{\circ} 04^{\prime} \mathrm{E}, 47^{\circ} 05^{\prime} \mathrm{N}-53^{\circ} 20^{\prime} \mathrm{N}\right)$, located in the northern Inner Mongolia Autonomous Region of China (Figure 1). The study area belongs to the continental monsoon climate region in the northern temperate zone, with long cold winters and short hot summers. The annual average temperature is $-1{ }^{\circ} \mathrm{C}$, the annual average precipitation is $500 \mathrm{~mm}$. Most precipitation occurs in July and August, and the annual average number of sunshine hours is 2735 . The region covers a wide range of grass types, including forest steppe, meadow steppe, and sandy steppe. This region is dominated by meadow steppe and its vegetation cover includes perennial bunch grasses that are formed in semihumid and semi-arid climatic conditions, including Stipa baicalensis, Leymus chinensis, Stipa grandis, Cleistogenes squarrosa, etc. The primary soil type in this region is chernozem, while others types include meadow chestnut soil, dark chestnut soil and chestnut soil. Natural resources are rich in the region, with 58 billion tons of proved coal reserves. Since the 1980s, overgrazing, wasteland reclamation, coal mining, and other industrial and agricultural developments have caused vegetation degradation, land desertification, pollution and salinization.

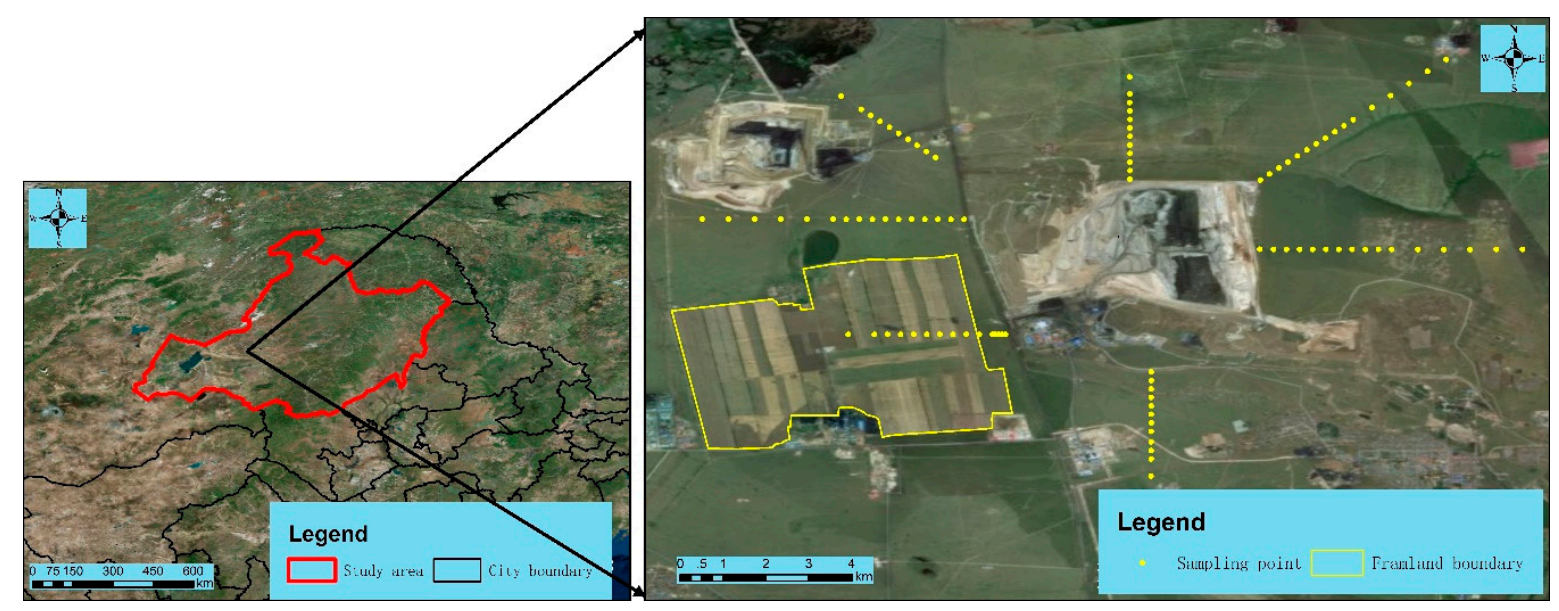

Figure 1. Study area location and sampling point distribution map.

\subsection{Materials}

A total of 112 soil sample points were set up around the Baorixile coal-mining zone in Hulun Buir Grassland in September 2017 (Figure 1). These points were roughly distributed among reclamation area and undisturbed area with varying degrees of ecological recovery. The points were followed by lines directed in east, northeast, north, northwest, west, and south, each line contained at least 15 points and each point was at a distance from 400 to $1000 \mathrm{~m}$. The sample points avoid rivers, roads, urban facilities, and grazing regions, but several samples were besides the agricultural area where wheat was planted. Each sample was obtained from 5 points of depth in the topsoil $(0-20 \mathrm{~cm})$ in a $1 \times 1 \mathrm{~m}$ quadrat; the point's soil was mixed and weighed to $\sim 500 \mathrm{~g}$. The samples were placed into self-sealing plastic bags and subsequently transported to the laboratory for air-drying. The concentrations of TOM, P, N, K, Cr, Cu, Zn, and Pb were measured by semi-micro Kjeldahl method and inductively coupled plasma mass spectrometry [42]. We also used Landsat-8 OLI L1B dataset from USGS in our analysis [43]. The specific raw image was acquired by satellite sensor on 2016/07/30 
(No. LC81240252016212LGN00), with no cloud. We preprocessed the image by atmospheric correction, radiometric calibration, and geometric correction, and then acquired the surface reflectance image. We calculated normalized difference vegetation index (NDVI, Equation (1)), and extracted NDVI values where our sampling points located. Then we calculated each sample's fractional vegetation cover (FVC, Equation (2)) [44]. The equation of NDVI and the equation of $F V C$ were in the form of

$$
\mathrm{NDVI}=\frac{R_{N I R}-R_{R E D}}{R_{N I R}+R_{R E D}}
$$

where $R_{N I R}$ represents the at-surface reflectivity obtained from sensor bands located in the near infrared and $R_{R E D}$ represents the reflectivity obtained from sensor bands located in red spectral regions.

$$
F V C=\frac{N D V I-N D V I_{\min }}{N D V I_{\max }-N D V I_{\min }}
$$

where $N D V I_{\min }$ represents NDVI for bare soil and $N D V I_{\max }$ represents NDVI for a vegetation.

\subsection{Descriptive Statistic Methods}

Two descriptive statistic methods were used to determine the soil nutrients reference condition. The concentrations of total organic matter (TOM), N, P, and K in soil were measured as depended variables. The population distribution method (PDM), which was proposed by U.S.EPA for the first time in 1998 [45], and the trisection method (TM), which is regarded as a complementary method of PDM and offered an conservative estimation, were used. PDM excluded the samples with severely impaired, then determined each variable's population distribution, finally selected the best quartile or lower 25th percentile of the distribution of each variable as the benchmark [46]. In this study, variable concentrations of the samples were arranged in order from large to small, $20 \%$ of impaired samples near the coal mine and road were excluded, then the best quartile threshold of each variable was set as the reference value. TM included all sample data, the median value derived from the best third of the sample database was set as the reference value [47].

\subsection{Regression Model Methods}

A multiple linear regression was used under the regression model method (RMM) to estimate the reference condition with best-fit techniques. Statistical analysis was performed using by SPSS v20 and all data were $\log _{10}$ transformed to accommodate heterogeneity of variance. There were many factors affecting soil nutrients quality including agricultural and livestock activities, industrial activities, and natural factors, so it was necessary to choose the suitable and available impact factors based on local ecological characteristics to improve accuracy of the model. Several potential impact factors of each sample were measured or calculated, including each sample's distance to the farm boundary, fractional vegetation cover $(F V C)$, the concentrations of $\mathrm{Pb}, \mathrm{Zn}, \mathrm{Cr}$, and $\mathrm{Cu}$ in soil. Since the study area belonged to the continental plateau, terrain conditions, such as slope, were not considered. The nutrient concentrations were dependent variables, the impact factors were independent variables (Equation (3)). A stepwise multiple regression was applied to determine the favorable model for attributing the effect on the nutrient yields. The regression model was in the form of

$$
y=b_{0}+\sum_{i=1}^{n} b_{i} x_{i}+e
$$

where $y$ is the depended variable and denotes the concentration of TOM, N, P, and $\mathrm{K} ; x_{i}$ denotes the independent variables and denote impact factors; $b_{0}$ is the intercept, $b_{i}$ denotes the regression coefficients for the independent variable, and $e$ represents the residual errors. 


\section{Results}

\subsection{Reference Conditions Established by Descriptive Statistic Methods}

Some of the samples that were near to the coal mine, road, or animal waste area and may be severely impaired, were excluded under PDM. Reference conditions of TOM, N, P, and K based on the dataset can be seen in Table 1 . The reference condition of TOM, N, P, and K by TM were $59.58 \mathrm{~g} / \mathrm{kg}$, $3.31 \mathrm{~g} / \mathrm{kg}, 2.17 \mathrm{mg} / \mathrm{kg}$, and $322.66 \mathrm{mg} / \mathrm{kg}$, respectively; while the reference condition by PDM were $54.49 \mathrm{~g} / \mathrm{kg}, 3.07 \mathrm{~g} / \mathrm{kg}, 1.96 \mathrm{mg} / \mathrm{kg}$, and $210.84 \mathrm{mg} / \mathrm{kg}$, respectively. The values of TM were all higher than that by PDM, meaning that TM was a more conservative estimation.

Table 1. TOM, N, P, and K distribution and reference condition by population distribution method (PDM) and trisection method (TM).

\begin{tabular}{ccccccc}
\hline Variable & Max & Top5\% & TM & PDM & Median & Top75\% \\
\hline TOM $(\mathrm{g} / \mathrm{kg})$ & 89.42 & 72.33 & 59.58 & 54.49 & 41.77 & 28.66 \\
N $(\mathrm{g} / \mathrm{kg})$ & 3.73 & 3.58 & 3.31 & 3.07 & 2.29 & 1.59 \\
$\mathrm{P}(\mathrm{mg} / \mathrm{kg})$ & 5.51 & 3.92 & 2.17 & 1.96 & 1.75 & 1.24 \\
$\mathrm{~K}(\mathrm{mg} / \mathrm{kg})$ & 628.02 & 425.42 & 322.66 & 299.60 & 210.84 & 122.60 \\
\hline
\end{tabular}

\subsection{Reference Conditions Established by Regression Model Method}

Identification of main anthropogenic impact factors would provide a basis for determining reference condition for grassland in human activity region. The distance to the farm boundary, the concentration of metal elements in soil and the FVC represented the degree of agricultural activity, industrial activity and local ecological status, respectively. Samples within a $5 \mathrm{~km}$ scope of farmland and sample FVC values $>0.2$ were analyzed in the regression model, in case of reducing sampling error. A stepwise regression analysis was made to find the best-fit model (Table 2). Two main factors, the distance to the farm and the FVC, affected the concentrations of the variables consistently in the TOM, N, and P models. The concentration of $\mathrm{Cr}$ had the negative relationship with the concentration of $\mathrm{K}$ in the model. The model with higher coefficients of determination $\left(\mathrm{R}^{2}\right)$ was selected to predict grassland soil reference condition of each variable, with significant ( $p$-values $<0.1$ ) independent variables. The $\mathrm{R}^{2}$ of the final regression model for TOM, N, $\mathrm{P}$, and K were $0.51,0.43$, 0.49 , and 0.47 , respectively.

Table 2. Regression models of different variables.

\begin{tabular}{ccccc}
\hline Variable & Model & $\mathbf{R}^{2}$ & S.E & $\mathbf{F}$ \\
\hline TOM & $\log ($ TOM $)=2.51-0.28 \log \left(\chi_{d}\right)$ & 0.37 & 0.14 & 31.09 \\
& $\log ($ TOM $)=2.64-0.27 \log \left(\chi_{d}\right)+0.53 \log \left(\chi_{v}\right)$ & 0.51 & 0.13 & 25.12 \\
$\mathrm{~N}$ & $\log (N)=1.05-0.22 \log \left(\chi_{d}\right)$ & 0.26 & 0.15 & 18.01 \\
& $\log (N)=1.15-0.19 \log \left(\chi_{d}\right)+0.59 \log \left(\chi_{v}\right)$ & 0.43 & 0.13 & 18.29 \\
$\mathrm{P}$ & $\log (P)=1.15-0.27 \log \left(\chi_{d}\right)$ & 0.34 & 0.15 & 26.10 \\
& $\log (P)=1.29-0.25 \log \left(\chi_{d}\right)+0.60 \log \left(\chi_{v}\right)$ & 0.49 & 0.14 & 23.28 \\
$\mathrm{~K}$ & $\log (K)=3.41-0.32 \log \left(\chi_{d}\right)$ & 0.36 & 0.17 & 28.72 \\
& $\log (K)=4.79-0.33 \log \left(\chi_{d}\right)-0.85 \log \left(\chi_{v}\right)$ & 0.43 & 0.16 & 18.79 \\
& $\log (K)=4.69-0.33 \log \left(\chi_{d}\right)-0.72 \log \left(\chi_{C r}\right)+0.36 \log \left(\chi_{v}\right)$ & 0.47 & 0.16 & 14.23 \\
\hline
\end{tabular}

$X_{d}, X_{v}$, and $X_{C r}$ represent the distance to the farm boundary, the $F V C$, and yield of $C r$, respectively.

As the soil characteristics varied, determined by both external and internal factors [48]. After the model was selected, model testing with 15 comparison samples was conducted. The results showed that all selected models performed well in this area by comparing the observed concentration of TOM, $\mathrm{N}, \mathrm{P}$, and $\mathrm{K}$ in east part of the study area with their predicted values by the selected models (Figure 2). Model fit was graphically depicted with $95 \%$ confidence limits. The $\mathrm{R}^{2}$ of models were $0.751,0.812$, 
0.709 , and 0.726 , respectively. Finally, the reference conditions for four variables by the regression model method were $42.30 \mathrm{~g} / \mathrm{kg}, 2.47 \mathrm{~g} / \mathrm{kg}, 2.13 \mathrm{mg} / \mathrm{kg}$, and $295.07 \mathrm{mg} / \mathrm{kg}$, respectively.

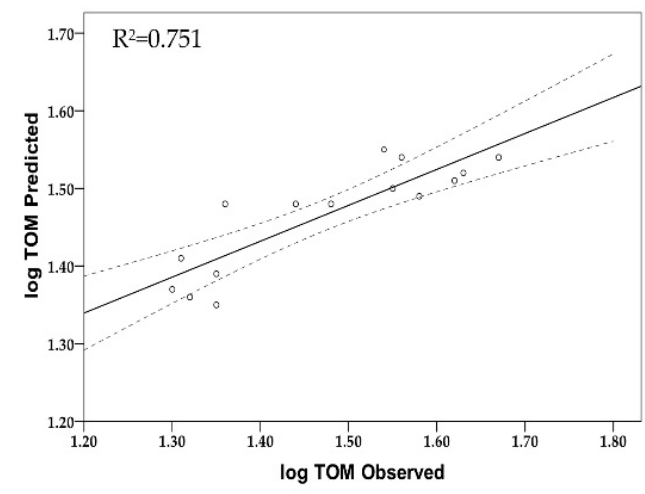

(a)

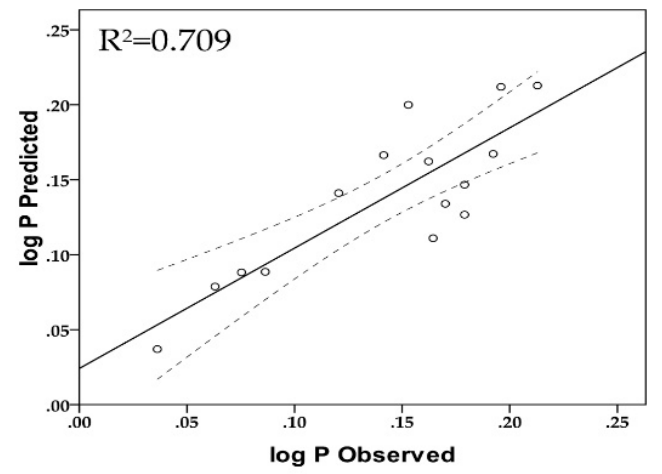

(c)

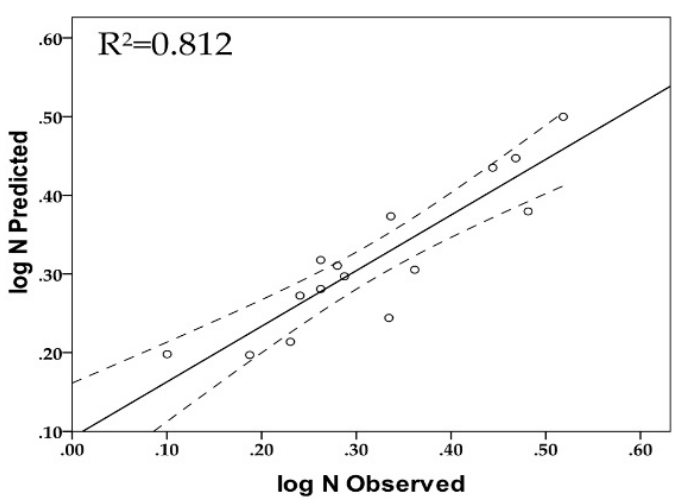

(b)

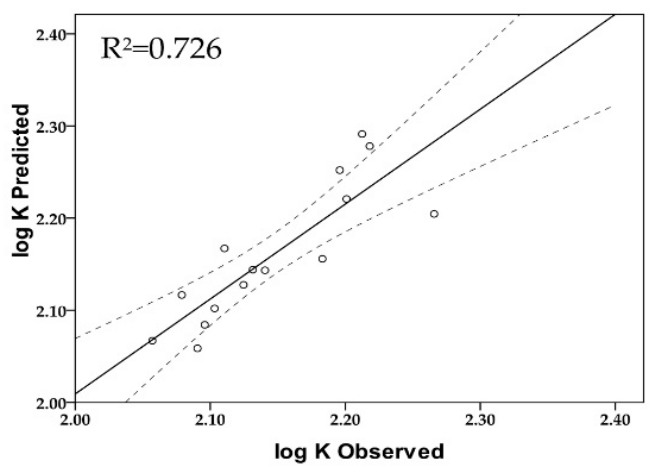

(d)

Figure 2. Comparison of predicted and observed concentration of variables. (a) Predicted concentrations by model and observed concentrations of TOM. (b) Predicted concentrations by model and observed concentrations of N. (c) Predicted concentrations by model and observed concentrations of P. (d) Predicted concentrations by model and observed concentrations of K. Model fit is graphically depicted with $95 \%$ confidence limits.

\subsection{Reference Conditions Recommendations}

The reference values determined by three methods presented small differences. The reference concentration value ranges of TOM, N, P, and K were 42.30 to $59.58 \mathrm{~g} / \mathrm{kg}, 2.47$ to $3.31 \mathrm{~g} / \mathrm{kg}$, 1.96 to $2.17 \mathrm{mg} / \mathrm{kg}$, and 295.07 to $322.66 \mathrm{mg} / \mathrm{kg}$, respectively. Based on the above results, the average reference nutrient concentrations determined by the three methods were set as the recommended reference condition in alpine regions of grassland of China, with the values of $52.12 \mathrm{~g} / \mathrm{kg}, 2.94 \mathrm{~g} / \mathrm{kg}, 2.08 \mathrm{mg} / \mathrm{kg}$, and $305.76 \mathrm{mg} / \mathrm{kg}$, respectively (Table 3).

Table 3. The reference condition by three methods and the historical record.

\begin{tabular}{cccc}
\hline Variable & Reference Condition & Historical Record & Historical Average \\
\hline TOM $(\mathrm{g} / \mathrm{kg})$ & 52.12 & $43.71-63.30$ & 53.51 \\
$\mathrm{~N}(\mathrm{~g} / \mathrm{kg})$ & 2.94 & $2.15-3.15$ & 2.65 \\
$\mathrm{P}(\mathrm{mg} / \mathrm{kg})$ & 2.08 & $0.12-4.02$ & 2.07 \\
$\mathrm{~K}(\mathrm{mg} / \mathrm{kg})$ & 305.76 & $182-283$ & 232.50 \\
\hline
\end{tabular}


In this study, a series of soil database in study area which regarded as historical data, were collected and analyzed [49]. One-hundred-and-seventy-six samples of nutrient concentrations in soil near the study areas were selected. The main soil type was chernozem and the sampling period was from 1998 to 2010. Compared with the historical data, the reference concentrations of TOM, N, and P were within the interval of the historical nutrients concentrations, while the reference concentrations of $\mathrm{K}$ was above the historical interval maximum value.

\section{Discussion}

\subsection{The Recommended Reference Conditions of Nutrients}

Through the above analysis, three methods were used to determine the soil nutrient reference condition in Hulun Buir Grassland. PDM showed lowest value of P, while RMM showed the lowest values for TOM, N, and K. TM showed the highest values for all nutrients. The difference ratio of TOM, $\mathrm{N}$, P, and $\mathrm{K}$ between values of TM and RMM were $40.86 \%, 35.27 \%, 2.35 \%$, and $9.35 \%$, respectively. The ranges of the four variables were $17.28 \mathrm{~g} / \mathrm{kg}, 0.86 \mathrm{~g} / \mathrm{kg}, 0.21 \mathrm{mg} / \mathrm{kg}$, and $27.59 \mathrm{mg} / \mathrm{kg}$, respectively. In other studies, the values by RMM were almost lower than that by the other methods, no matter in water ecosystem or wetland ecosystem $[50,51]$. The results in grassland ecosystem were similar to the studies in other ecosystem. We set the median values as the recommended reference conditions to reduce the error caused by methods.

In this study, the variations between reference values of TOM, N, P, and historical average values were $2.66 \%, 10.94 \%$, and $4.83 \%$, respectively. However, the reference value of $\mathrm{K}$ was $31.5 \%$ higher than the historical average value. After the a series of observations, we found that multiple amounts of potash fertilizer were applied, more wheat was cultivated, and less precipitation occurred in recent years, causing a higher current value of $\mathrm{K}$ than historical value. It would be a huge deviation to choose the historical data as the reference condition. What is more, data from National Hulun Buir Grassland Ecosystem Observation and Research Station cannot be the reference condition because the soils in the station were well protected and the nutrient concentrations of soils in the station were far higher than that outside the station. The condition should be regarded as the best attainable condition rather than reference condition [14]. Thus, choosing the conditions by three methods using in this study are more practical and accurate than historical condition in making management decisions.

\subsection{The Factors That Affect the Results}

The extreme values would affect the results of PDM and TM. When the extreme high values accounted for $15 \%$ of total data, the reference condition by TM would appear to deviate from the natural background value; if the extreme high values accounted for $25 \%$ of total data, the reference condition by both TM and PDM would be overvalued. For RMM, the significant predictors of variables will affect accuracy of the model. Almost all nutrient concentrations of samples in other ecosystems were affected by agricultural activities, livestock/poultry breeding, and human population [50]. In this study, two main impact factors affected the concentration of nutrients in soil, one was the distance to the farm boundary, and the other was the vegetation coverage, they were all had positive relationships with the concentration of nutrients. These findings are also similar to other studies in aquatic systems [48,52]. Because of fertilization of farmlands by humans to improve the production of wheat, samples near the farm had more chances to be fertilized consciously or unconsciously. Also, a more sufficient supply of water was available in the soils near the farmland and livestock/poultry breeding waste had more density near the farmland. These factors evidently contributed to increasing concentrations of nutrients in soil [53]. Although the study area was located in the opencast mine area, industrial activity, which was measured by the distance to the mine boundary and the concentrations of heavy metal, brought little impact on the concentration of nutrients. This mean that agricultural disturbance affected soil nutrients' concentration more than that of industrial activity. This finding was a little different from results in the aquatic system $[15,54]$. A probable explanation for this finding was that the contaminants 
from industrial activities were more easily spread in water than that in soil or, the contaminants were absorbed by plants, causing a lower concentration in soil.

Besides, another important finding was that the influence of the agricultural activity to the concentration of soil nutrients had limited radius. The regression model became insignificant gradually when the distance from sample site to the farm boundary exceeded $5 \mathrm{~km}$. Samples which distance from farmland less than or equal to $4.5 \mathrm{~km}$ were analyzed in this study, in order to guarantee the prediction accuracy. As a result, when regression model is used terrestrial ecosystem, the evaluation scope should not be too large.

\subsection{The Adaptive Analysis of Three Methods}

Three methods had their own advantages and limitations in determination of reference condition. The calculation of PDM and TM were simple and feasible, and the results were in high comparability. With the extension of the study area, the dominant species, physical and chemical properties of soil and climatic conditions would be dissimilar. As a result, expert judgment and local environmental laws or criteria should be combined to minimize or account for systematic prediction bias, and adjustments of human interference should be added. Also, subdivision of the variables under these methods may be established where there were adequate monitoring stations and data [18,31].

If data was scarce, RMM may be necessary to determine the reference condition. As the risk factors were different, the independent variables would be different accordingly, such as land-use patterns, nutrition deposition rate, runoff, or other yields of nutrients $[17,47,55]$. The key work for this method was to identify the main corresponding anthropogenic factors, but when the anthropogenic factors were insufficient, the application of this method was constrained. In this study, the $\mathrm{R}^{2}$ of models were from 0.43 to 0.51 . In order to increase the goodness of fit, an exclusion of extreme values and an increase number of independent variables in the model were needed [21,56]. This method was suitable in areas where suffered anthropogenic disturbance and worked only if small or moderately affected systems were available and if modeling assumptions were met. However, there was a dilemma that reference condition was aiming to find an area condition without human disturbance, but this area was always unreachable or immeasurable, where the data were either insufficient or unavailable. The most drawback of RMM is that it depends on the quality of existing data, reducing its applicability within areas where long-time data are not available, but when the samples are insufficient or reference reaches are not available, RMM is the only option to determine the reference condition.

\subsection{Management Suggestion}

Even though the reference condition is the vital to grassland protection, grassland ecosystems have their own characters and difficulties when determining the reference condition. First of all, grasslands are distributed in sparsely populated areas [57], lacking data such as grazing and fire frequency. Identifying the condition without human activities is impossible due to the absence of any descriptive material [58]. Secondly, the condition of grassland has been altered at a large scale, making the current condition different from its historical one. Thirdly, data from observation stations cannot be the reference condition for most grassland area because the grazing intensity, which can changes plant community composition and soil microbial biomass, are different among regions. Actually, there is no better option than using data from pristine sites to determine reference condition, although many methods can be used simultaneously to provide different conditions for comparison. A hierarchical preference order should be considered for assigning official threshold values. The methods which satisfy the following criteria should be used preferentially: (1) if the method can be used to measure existing conditions; (2) if the procedure is rapid and cost-saving; (3) if the process of site visit and sampling are involved; and (4) if the results can be verified [59]. When the previous methods cannot be used, historical data method and experts' judgment method would be the substitute methods.

The soil quality of grasslands in China has continued to evolve spatially, with most soil conditions in northern provinces and areas having a steady deteriorating trend. Some efforts have been made 
to improve the soil condition in northern grassland areas, such as restricting intensive grazing and delimiting protection zone. The background nutrient concentrations based on our study can provide an indication of the natural trophic state of soil in local area. The reference values can test the degree of soil erosion and biological habitat destruction caused by coal mining and agricultural activities. The reference values can also reasonably classify the land productivity of reclaimed cultivated land, and clarify factors such as productivity and soil fertility.

The land reclamation work in study area usually used excavators and other large-scale machinery. The reclamation materials were from the original soil of mining areas and imported soil. The factors of equipment, reclamation materials, and reclamation technology will directly affect the success of soil reclamation. Based on the reference conditions we set, the managers can testify the physical and chemical properties of soil, and evaluate the soil remediation effect in subsidence area or reclamation area besides the open-pit coal mine, where land reclamation project had be constructed years ago. Also, based on the impact factors the study found, the managers can increase investment in precision fertilization and introduction of drought-resistant grass species to reduce the ecological pressures in local area. The methods using in this study can be a manual to set nutrient criteria in other grassland areas, which have suffered from different disturbances such as urban expansion and overgrazing.

\section{Conclusions}

The reference condition is an important part of ecological assessment and a prerequisite for establishing grassland soil nutrient criteria or standard, especially useful in grassland area with different anthropologic impacts. In this article, three methods-the population distribution method, the trisection method, and the regression model method-were used to determine the soil nutrients reference condition in alpine region grassland of Hulun Buir. The concentrations of TOM, N, P, and K in soil were the variables of the reference condition. The results from the three methods presented that the reference concentration value ranges of TOM, N, P, and K were 42.30 to $59.58 \mathrm{~g} / \mathrm{kg}, 2.47$ to $3.31 \mathrm{~g} / \mathrm{kg}$, 1.96 to $2.17 \mathrm{mg} / \mathrm{kg}$, and 295.07 to $322.66 \mathrm{mg} / \mathrm{kg}$, respectively; the average concentrations of TOM, N, P, and K in soil were $52.12 \mathrm{~g} / \mathrm{kg}, 2.94 \mathrm{~g} / \mathrm{kg}, 2.08 \mathrm{mg} / \mathrm{kg}$, and $305.76 \mathrm{mg} / \mathrm{kg}$, respectively. The concentrations of TOM, N, and P were similar to the historical data, while the concentration of $\mathrm{K}$ was 31.5\% higher than historical record from 1998 to 2010. The regression analysis suggested that the major impact factors on grassland soil nutrients quality in the study area were agricultural activity and vegetation coverage, rather than coal mining activity. In practical operation, a hierarchical preference order of methods should be established to obtain an accurate reference value. If the reference sites are available, three methods used in this study are recommended preferentially; if the reference sites are unavailable, historical data and experts' judgment may be used. Although many methods were studied in past years and in many ecosystems, researchers should get fully awareness of the strengths and weaknesses of the datasets and methods they work with, and of the target they want to achieve, then choose the appropriate method to analyze and determine the condition. In all, the definition, methodology, and procedure of the reference condition are key elements for successful assessment of threatened grassland; these elements could help local managers better understand their environment status and the problems that is faces allowing them to then take more effective measures to facilitate recovery of the grassland ecosystem.

Author Contributions: G.W. designed the study and revised and approved the final manuscript, J.L., F.C., and X.F. collected the data; J.L. wrote the first manuscript; D.W. conducted data analysis and provided critical comments on the manuscript; and Y.T. provided critical comments on the manuscript and edited the manuscript for intellectual content. All authors read and approved the final manuscript.

Funding: Ministry of Science and Technology, People's Republic of China: 2016YFC0503603. Ministry of Science and Technology, People's Republic of China: 2016YFC0501101.

Acknowledgments: This work was supported primarily by the State Key Research Development Program of China (No. 2016YFC0503603), (No. 2016YFC0501101). We also want to thank Jing Li from China University of Mining and Technology for invaluable assistance with samples collection and detection. 
Conflicts of Interest: The authors declare no conflicts of interest.

\section{References}

1. White, R.P.; Murray, S.; Rohweder, M.; White, R.P.; Murray, S.; Rohweder, M. Pilot analysis of global ecosystems: Grassland ecosystems. World Resour. Inst. 2000, 4, 275.

2. Lauenroth, W.K.; Burke, I.C.; Gutmann, M.P. The structure and function of ecosystems in the central north American grassland region. Great Plains Res. 1999, 9, 223-259.

3. Xu, Y.; Wan, S.; Cheng, W.; Li, L. Impacts of grazing intensity on denitrification and $\mathrm{N}_{2} \mathrm{O}$ production in a semi-arid grassland ecosystem. Biogeochemistry 2008, 88, 103-115. [CrossRef]

4. Costanza, R.; d'Arge, R.; Groot, R.D.; Farber, S.; Grasso, M.; Hannon, B.; Limburg, K.; Naeem, S.; O’Neill, R.V.; Paruelo, J. The value of the world's ecosystem services and natural capital 1. World Environ. 1997, 387, 3-15. [CrossRef]

5. Balvanera, P.; Pfisterer, A.B.; Buchmann, N.; He, J.S.; Nakashizuka, T.; Raffaelli, D.; Schmid, B. Quantifying the evidence for biodiversity effects on ecosystem functioning and services. Ecol. Lett. 2010, 9, 1146-1156. [CrossRef] [PubMed]

6. Liu, G.H.; Fu, B.J.; Chen, L.D.; Guo, X.D. Characteristics and distributions of degraded ecological types in China. Acta Ecol. Sin. 2000, 20, 13-19.

7. Wang, L.Y.; Xiao, Y.; Rao, E.M.; Jiang, L.; Xiao, Y.; Ouyang, Z.Y. An assessment of the impact of urbanization on soil erosion in Inner Mongolia. Int. J. Environ. Res. Public Health 2018, 15, 550. [CrossRef] [PubMed]

8. Karlen, D.L.; Mausbach, M.J.; Doran, J.W.; Cline, R.G.; Harris, R.F.; Schuman, G.E. Soil quality: A concept, definition, and framework for evaluation (a guest editorial). Soil Sci. Soc. Am. J. 2017, 61, 4-10. [CrossRef]

9. Seybold, C.A.; Mausbach, M.J.; Karlen, D.L.; Rogers, H.H.; Lal, R.; Kimble, J.M.; Follett, R.F.; Stewart, B.A. Quantification of soil quality. In Soil Processes and the Carbon Cycle; Lal, R., Kimble, J.M., Follett, R.F., Eds.; CRC Press: Boca Raton, FL, USA, 1998; pp. 387-404.

10. Zeng, Q.; Liu, Y.; Li, X.; Huang, Y. How fencing affects the soil quality and plant biomass in the grassland of the loess plateau. Int. J. Environ. Res. Public Health 2017, 14, 1117. [CrossRef]

11. Heneghan, L.; Miller, S.P.; Baer, S.; Callaham, M.A., Jr.; Montgomery, J.; Pavao-Zuckerman, M.; Rhoades, C.C.; Richardson, S. Integrating soil ecological knowledge into restoration management. Restor. Ecol. 2010, 16, 608-617. [CrossRef]

12. Hughes, R.M. Defining acceptable biological status by comparing with reference conditions. In Biological Assessment and Criteria: Tools for Water Resource Planning and Decision Making; Davis, W.S., Simon, T.P., Eds.; CRC Press: Boca Raton, FL, USA, 1995; pp. 31-48.

13. Reynoldson, T.B.; Wright, J.F.; Wright, J.F.; Sutcliffe, D.W.; Furse, M.T. The reference condition: Problems and solutions. In Proceedings of the International Workshop on Assessing the Biological Quality of Fresh Waters: Rivpacs and Other Techniques, Oxford, UK, 16-18 September 2000.

14. Stoddard, J.L.; Larsen, D.P.; Hawkins, C.P.; Johnson, R.K.; Norris, R.H. Setting expectations for the ecological condition of streams:The concept of reference condition. In Proceedings of the American Geophysical Union 2005 Joint Assembly, New Orleans, LA, USA, 23-27 May 2005; pp. 1267-1276.

15. Hawkins, C.; Olson, J.; Hill, R. The reference condition: Predicting benchmarks for ecological and water-quality assessments. J. N. Am. Benthol. Soc. 2010, 29, 312-343. [CrossRef]

16. Karr, J.R. Biological integrity: A long-neglected aspect of water resource management. Ecol. Appl. 1991, 1, 66-84. [CrossRef] [PubMed]

17. Reece, P.F.; Richardson, J.S. Biomonitoring with the reference condition approach for the detection of aquatic ecosystems at risk. In Proceedings of the Conference on the Biology and Management of Species and Habitats at Risk, Kamloops, BC, Canada, 15-19 February 1999; Volume 15, pp. 549-552.

18. Smith, R.A.; Alexander, R.B.; Schwarz, G.E. Natural background concentrations of nutrients in streams and rivers of the conterminous United States. Environ. Sci. Technol. 2003, 37, 3039-3047. [CrossRef] [PubMed]

19. Paul, M.J.; Gerritsen, J. Nutrient Criteria for Florida Lakes: A Comparison of Approaches; Prepared for the Florida Department of Environmental Protection: Tallahassee, FL, USA, 2002.

20. Knowlton, M.F. Role of land cover and hydrology in determining nutrients in mid-continent reservoirs: Implications for nutrient criteria and management. Lake Reserv. Manag. 2008, 24, 1-9. 
21. Huo, S.; Xi, B.; Su, J.; Zan, F.; Chen, Q.; Ji, D.; Ma, C. Determining reference conditions for tn, tp, sd and chl-a in eastern plain ecoregion lakes, China. J. Environ. Sci. 2013, 25, 1001-1006. [CrossRef]

22. Zhang, L.; Huo, S.; Zhou, Y.; Tong, Z. Establishing lake reference conditions for nutrient criteria based on system dynamics. Acta Sci. Circumstantiae 2011, 31, 1254-1262.

23. Fulé, P.Z.; Covington, W.W.; Moore, M.M. Determining reference conditions for ecosystem management of southwestern ponderosa pine forests. Ecol. Appl. 1997, 7, 895-908. [CrossRef]

24. Karr, J.R.; Kimberling, D.N. A terrestrial arthropod index of biological integrity for shrub-steppe landscapes. Northwest Sci. 2003, 77, 202-213.

25. Lopez, R.D.; Fennessy, M.S. Testing the floristic quality assessment index as an indicator of wetland condition. Ecol. Appl. 2002, 12, 487-497. [CrossRef]

26. Rose, P.M.; Kennard, M.J.; Moffatt, D.B.; Fran, S.; Butler, G.L. Testing three species distribution modelling strategies to define fish assemblage reference conditions for stream bioassessment and related applications. PLoS ONE 2016, 11, e0146728. [CrossRef]

27. Orfanidis, S.; Panayotidis, P.; Ugland, K. Ecological evaluation index continuous formula (EEI-c) application: A step forward for functional groups, the formula and reference condition values. Mediterr. Mar. 2012, 12, 199-231. [CrossRef]

28. Mack, J.J. Landscape as a predictor of wetland condition: An evaluation of the landscape development index (LDI) with a large reference wetland dataset from Ohio. Environ. Monit. Assess. 2006, 120, 221-241. [CrossRef] [PubMed]

29. Elias, C.L.; Calapez, A.R.; Almeida, S.F.P.; Chessman, B.; Simões, N.; Feio, M.J. Predicting reference conditions for river bioassessment by incorporating boosted trees in the environmental filters method. Ecol. Indic. 2016, 69, 239-251. [CrossRef]

30. Suplee, M.W.; Varghese, A.; Cleland, J. Developing nutrient criteria for streams: An evaluation of the frequency distribution method. JAWRA J. Am. Water Resour. Assoc. 2010, 43, 453-472. [CrossRef]

31. Hughes, R.M.; Larsen, D.P.; Omernik, J.M. Regional reference sites: A method for assessing stream potentials. Environ. Manag. 1986, 10, 629-635. [CrossRef]

32. Bamber, J.L.; Aspinall, W.P. An expert judgement assessment of future sea level rise from the ice sheets. Nat. Clim. Chang. 2013, 3, 424-427. [CrossRef]

33. Dodds, W.; Carney, E.; Angelo, R. Determining ecoregional reference conditions for nutrients, secchi depth and chlorophyll a in kansas lakes and reservoirs. Lake Reserv. Manag. 2006, 22, 151-159. [CrossRef]

34. Wallin, M.; Wiederholm, T.; Johnson, R.K. Guidance on establishing reference conditions and ecological status class boundaries for inland surface waters. Cis Work. Group 2003, 2, 93.

35. USEPA. Nutrient Criteria Technical Guidance Manual: Rivers and Streams; U.S. Environmental Protection Agency: Office of Science and Technology, Office of Water: Washington, DC, USA, 2000.

36. Dodds, W.K.; Oakes, R.M. A technique for establishing reference nutrient concentrations across watersheds affected by humans. Limnol. Oceanogr. Methods 2004, 2, 333-341. [CrossRef]

37. Carrel, G. Prospecting for historical fish data from the rhone river basin: A contribution to the assessment of reference conditions. Arch. Fur Hydrobiol. 2002, 155, 273-290. [CrossRef]

38. Muxika, I.; Borja, A.; Bald, J. Using historical data, expert judgement and multivariate analysis in assessing reference conditions and benthic ecological status, according to the European water framework directive. Mar. Pollut. Bull. 2007, 55, 16-29. [CrossRef] [PubMed]

39. Shi-Long, P.; Yu, X. Spatial distribution of grassland biomass in China. Acta Phytoecol. Sin. 2004, 28, 491-498. [CrossRef]

40. Wu, D.; Chen, D.; Tang, L.; Shao, G. A comprehensive assessment of ecological sensitivity for a coal-fired power plant in xilingol, inner mongolia. Int. J. Sustain. Dev. World Ecol. 2016, 24, 1-7. [CrossRef]

41. Hui, F.; Zhongke, B.; Shuli, Z.; Fangdai, M.; Suiquan, W. Ecological damage prediction and restoration of coal minein hulun buir grassland. Trans. Chin. Soc. Agric. Eng. 2008, 2008. [CrossRef]

42. Bremner, J.M.; Breitenbeck, G.A. A simple method for determination of ammonium in semimicro-Kjeldahl analysis of soils and plant materials using a block digester. Commun. Soil Sci. Plant Anal. 1983, 14, 905-913. [CrossRef]

43. USGS Global Visualization Viewer. Available online: https://glovis.usgs.gov/ (accessed on 22 November 2018). 
44. Jimenez-Munoz, J.C.; Sobrino, J.A.; Plaza, A.; Guanter, L.; Moreno, J.; Martã-Nez, P. Comparison between fractional vegetation cover retrievals from vegetation indices and spectral mixture analysis: Case study of proba/chris data over an agricultural area. Sensors 2009, 9, 768-793. [CrossRef] [PubMed]

45. USEPA. Lake and Reservoir Bioassessment and Biocriteria Technical Guidance Document; U.S. Environmental Protection Agency, Office of Science and Technology, Office of Water: Washington, DC, USA, 1998.

46. Angradi, T.R.; Bartsch, W.M.; Trebitz, A.S.; Brady, V.J.; Launspach, J.J. A depth-adjusted ambient distribution approach for setting numeric removal targets for a great lakes area of concern beneficial use impairment: Degraded benthos. J. Great Lakes Res. 2017, 43, 108-120. [CrossRef]

47. Gibson, G.; Carlson, R.; Simpson, J.; Smeltzer, E.; Chapra, S.; Heiskary, S.; Jones, J.; Kennedy, R. Nutrient Criteria Technical Guidance Manual Lakes and Reservoirs; U.S. Environmental Protection Agency: Office of Science and Technology, Office of Water: Washington, DC, USA, 2000.

48. Moss, B.; Stephen, D.; Alvarez, C.; Becares, E.; Bund, W.V.D.; Collings, S.E.; Donk, E.V.; Eyto, E.D.; Feldmann, T.; Fernández-Aláez, C. The determination of ecological status in shallow lakes-A tested system (ecoframe) for implementation of the european water framework directive. Aquat. Conserv. Mar. Freshw. Ecosyst. 2010, 13, 507-549. [CrossRef]

49. China Soil Database. Available online: http://vdb3.soil.csdb.cn/ (accessed on 22 November 2018).

50. Jiabo, C.; Jun, L. Establishment of reference conditions for nutrients in an intensive agricultural watershed, eastern China. Environ. Sci. Pollut. Res. 2014, 21, 2496-2505.

51. Cheng, P.; Li, X. Establishing reference nutrient conditions using improved statistical methods in a river network with typical monsoon climatic pattern. Ecol. Indic. 2018, 89, 260-268. [CrossRef]

52. Huo, S.; Xi, B.; Su, J.; He, Z.; Zan, F.; Yu, H. Defining physico-chemical variables, chlorophyll-a and secchi depth reference conditions in northeast eco-region lakes, China. Environ. Earth Sci. 2014, 71, 995-1005. [CrossRef]

53. Yang, Y.; Chen, Y.; Zhang, X.; Ongley, E.; Zhao, L. Methodology for agricultural and rural nps pollution in a typical county of the north China plain. Environ. Pollut. 2012, 168, 170-176. [CrossRef] [PubMed]

54. Moreno, J.; Navarro, C.; De las Heras, J. Abiotic ecotypes in south-central spanish rivers: Reference conditions and pollution. Environ. Pollut. 2006, 143, 388-396. [CrossRef] [PubMed]

55. USEPA. National Rivers and Streams Assessment 2008-2009: A Collaborative Survey(epa/841/r-16/007); U.S. Environmental Protection Agency: Office of Water and Office of Research and Development: Washington, DC, USA, 2016.

56. Kennard, M.J.; Harch, B.D.; Pusey, B.J.; Arthington, A.H. Accurately defining the reference condition for summary biotic metrics: A comparison of four approaches. Hydrobiologia 2006, 572, 151-170. [CrossRef]

57. Griffith, G.W.; Roderick, K. Saprotrophic Basidiomycetes in Grasslands: Distribution and Function; Elsevier Science \& Technology: Amsterdam, Netherlands, 2008; pp. 277-299.

58. Kaufmann, M.R. Forest Reference Conditions for Ecosystem Management in the Sacramento Mountains, New Mexico; General Technical Report RMRS-GTR-19; U.S. Department of Agriculture, Forest Service, Rocky Mountain Research Station: Fort Collins, CO, USA, 1998.

59. Fennessy, M.S.; Jacobs, A.D.; Kentula, M.E. An evaluation of rapid methods for assessing the ecological condition of wetlands. Wetlands 2007, 27, 543-560. [CrossRef]

(C) 2018 by the authors. Licensee MDPI, Basel, Switzerland. This article is an open access article distributed under the terms and conditions of the Creative Commons Attribution (CC BY) license (http://creativecommons.org/licenses/by/4.0/). 